Research Article

www.jestr.org

\title{
Experimental and Numerical Thermal Analysis of Formula Student Racing Car Disc Brake Design
}

\author{
Manthan Vidiya ${ }^{1, *}$ and Balbir Singh ${ }^{2}$ \\ ${ }^{I}$ Department of Mechanical and Manufacturing Engineering Manipal Institute of Technology, Manipal University, Manipal, 576104 \\ INDIA. \\ ${ }^{2}$ Department of Aeronautical and Automobile Engineering, Manipal institute of Technology, Manipal University, Manipal, 576104 INDIA.
}

Received 2 January 2017; Accepted 17 March 2017

\begin{abstract}
Formula racing car brakes undergo massive loading not only mechanical, but thermal as well. There are various problems that occur due to brake assembly components reaching very high temperatures such as brake fade, induction of thermal stresses and chances of thermo-mechanical fatigue of components taking the braking loads. Hence analyzing the brake components for thermal loads becomes very important. This paper deals with the theory behind thermal analysis of the brake, the method used to calculate the conversion of the car's kinetic energy to the brake's heat energy, to find the convection coefficient available due to the air flow on the car and to determine the overall temperature rise on the brake disc. This paper shows simulations conducted in various software and the data as well as the graphs obtained from these simulations. Similar type of data and graphs are obtained from the actual testing with the use of various sensors mounted on the car. In the end there is a comparison made between the simulation and the data obtained from the car's testing to verify the method used for its accuracy and reliability.
\end{abstract}

Keywords: Formula Student Car; Operating Temperature; Brake Performance; ANSYS; Brake Fade; Convection Coefficient.

\section{Introduction}

Overheating of brakes happens due to many reasons such as heavy braking, prolonged braking, insufficient cooling etc. [1]. Brake fade is the biggest problem that is associated with rise in temperature which leads to boiling of the brake fluid, gassing and glazing of brake pads and hence reducing braking performance [2] Therefore, the brake components should be designed taking the thermal effects in mind. Pradnya Kosbe and Chittaranjan More have described the characteristics of fade and the recovery behavior of the brakes [3]. Various studies have been made earlier to determine the brake temperature rise for single braking [4][5][6] but this paper takes the analysis a step further by being able to analyze the temperature throughout a lap of a track and for various such laps. The papers [7][8] only shows the rise in temperature for single braking, whereas this paper analyzes the operating temperature that the brakes would achieve once an equilibrium is established between the heat generation and dissipation hence will serve as a good basis for thermal optimization of brakes for a formula student car.

\subsection{About Formula Student Racing Car}

'Formula Manipal' is the official Formula student team of Manipal University, India. The vehicle dynamics team of this project works on the thermal of brake components as well as performs tests of the race car. The car used for testing is called FMX6. It is a single seater, open wheel,

E-mail address: manthanvidiya96@gmail.com

ISSN: $1791-2377$ @ 2017 Eastern Macedonia and Thrace Institute of Technology. All rights reserved. formula style racing car designed and manufactured by the students of the Manipal Insti tute of Technology, a constituent institute of Manipal University, India. It is the team's seventh car weighing $200 \mathrm{~kg}$ with a Honda CBR 600rr engine, 10 inch wheels, an aero package and stainless steel brake discs on front and the rear wheel with floating brake discs. We used disc brake system in this car due to the advantages such as effective cooling, less weight, selfcleaning action etc. described by Er. N.B.Shinde, Prof. B.R.Borkar [9] and Subhasis Sarkar, Prof. (Dr.) Pravin P. Rathod [10]. Fig. 1 shows the snapshot of this racing car. As weight reduction was one the primary goals for this car, there was a significant weight reduction in the brake disc. Due to the shift from 13 inch rims to 10 inch rims, the size of the brake disc had to be reduced. As the brake disc acts as a heat sink, mass of the disc plays an important role in heat carrying capacity of the disc. There was a plan to include an aero package in the car. Because of this, the air coming onto the brakes was obstructed by the front wings. Due to all these factors combined, there was a high risk of our brakes becoming too hot and the brake fluid boiling. This could not be allowed as it would affect the car's performance drastically during the endurance event. Hence we decided to find out the operating temperature of our brakes with the help of thermal analysis. Endurance event is a race event in the Formula Student competition where the car has to run continuously for 22 kilometers without any failure with timed laps on a pre-determined race track.

\subsection{The Brake Disc}

The important requirements of the brake disc are as described by Mr. Sachin Subhashrao Pujari, Prof. Mr. K. M. Narkar and Mr. Kishor T. Phalke [4]: 
- It should provide a surface having well anti wear qualities.

- It should allow the optimum rate of heat transfer.

- Heat is generated at every cycle of brake application and must be dissipated to the atmosphere.

- $\quad$ Sufficient strength and minimum weight.

- It must be accommodate within the minimum space available.

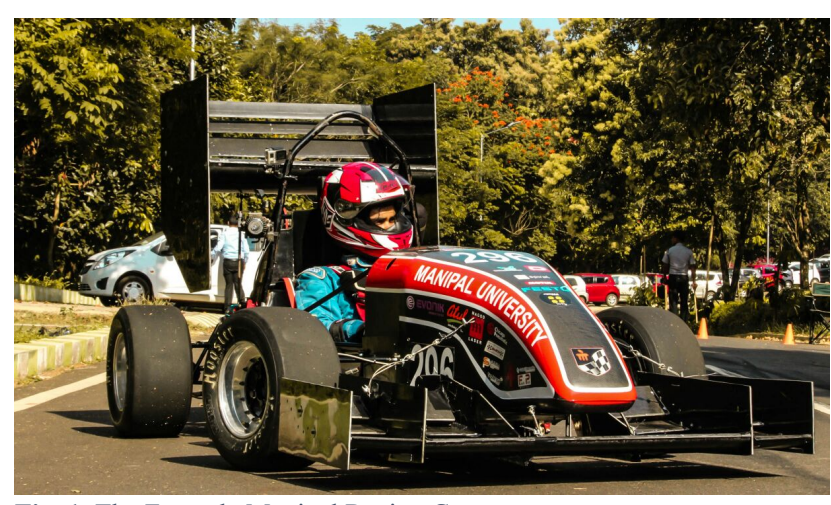

Fig. 1. The Formula Manipal Racing Car
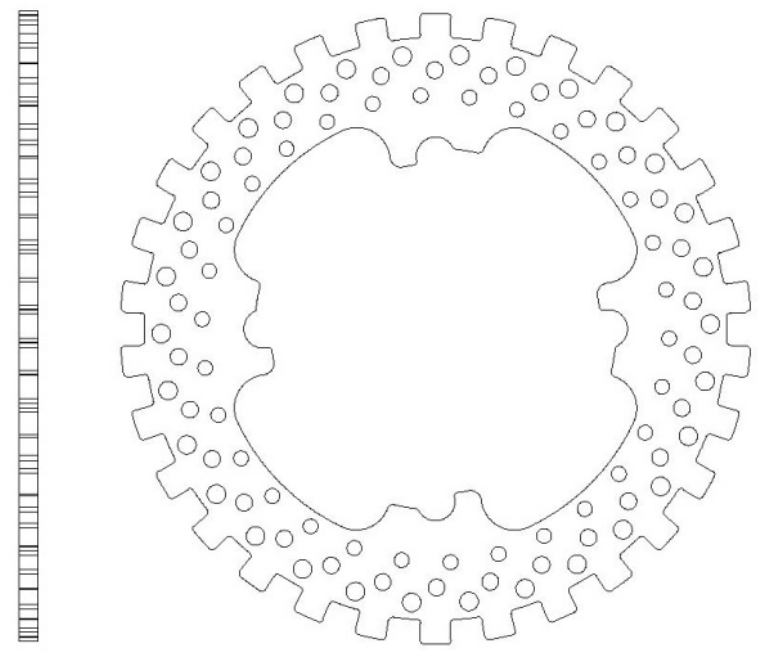

Front view

Left view

Fig. 2. 2D draft and $3 \mathrm{D}$ render of the brake disc

\section{Background Theory}

The equations used in this paper along with their relative theories are given below. For calculating the working temperature of the brake, it is important to understand that the basic function of brakes is to convert the kinetic energy of the car into heat energy through friction [5]. This kinetic energy is not entirely sent to the brakes but also lost due to friction between parts, wear and tear of parts, drag etc. Since it is difficult to calculate the kinetic energy loss in the vehicle and the actual energy being transmitted to the brakes, we can find the heat generated at the brakes with another equation. Since we know

$$
\text { Power }=\text { Force } \times \text { change in velocity }
$$

We can use this principle on the rotor and pad contact patch. L. Kowal, K. Turewicz and T. Kruczek [7] have
The brake disc used on the car was made from stainless steel 410 and had a diameter of $170 \mathrm{~mm}$ and a PCD of 90 $\mathrm{mm}$ for mounting on the wheel hub. Stainless steel was used as disc material due to advantages described in [12].The Disc weighed 360 grams and was of a drilled type to ensure maximum heat dissipation by the air. It is completely designed and manufactured by the vehicle dynamics team of MIT, Manipal. Fig. 2 shows the 2D draft and 3D render of the designed brake disc. The brake disc has teeth on its circumference to be used to measure the wheel RPM using the Hall Effect sensor.

described an equation to calculate the heat input on the brake disc. It states that heat flux on the rotor is equal to the friction force due to braking times the change in velocity of the disc produced due to braking.

$$
H=F_{f} \times \Delta v
$$

The friction force generated can be calculated using the equation given by Saeed Abu Alyazeed Albatlan [12] and Swapnil R. Abhang, D.P.Bhaskar [13].

$$
F_{f}=\mu_{d} \times A_{p} \times p r \times n
$$

The heat is generated on the brake pad and disc contact. Faramarz Talati, Salman Jalalifar [8] have shown how the heat is distributed on the pad surface. The heat distribution between the brake pad and disc depends upon the surface area as well as the material properties of both the 
components. When the contact is taken into account the heat partition coefficient is given by:

$p=\frac{\sqrt{k_{d} \rho_{d} c_{d}} \times s_{d}}{\sqrt{k_{d} \rho_{d} c_{d}} \times S_{d}+\sqrt{k_{p} \rho_{p} c_{d}} \times S_{p}}$

Where $k_{d}$ is the thermal conductivity of the disc. The term $\sqrt{k \rho c}$ is known as the thermal effussivity of the material. Hence the heat absorbed by the disc is given by:

$$
\left(H_{d}\right)=p \times H
$$

Heat absorbed by the brake pad is given by:

$$
\left(H_{p}\right)=(1-p) \times H
$$

After finding the heat input, it is important to find the heat dissipation to determine the rise in temperature. Convection plays the most important role in cooling of brakes. Convection here is defined as the phenomena of heat being carried away by the air flowing over the brake components. Heat lost from a body due to convection depends on the surface area, specific heat and the convection coefficient of the body as described by Ali Belhocine and Mostefa Bouchetara [14]. Hence the heat lost in convection is given by:

$$
H_{\text {convection }=h \times A \times \Delta T}
$$

The amount of surface area of the disc that can be increased is limited by the wheel size and weight restrictions. Hence it becomes very important to maximize convection coefficient which depends upon the boundary layer which is affected by the surface geometry, fluid motion and thermodynamic as well as fluid transfer properties [15].

Radiation adds to the cooling effect of the brakes by dissipating the heat energy in the form of waves [16]. The heat dissipated by radiation is given by:

$$
H_{\text {radiation }}=\sigma \times A \times \Delta \mathrm{T}^{4}
$$

Temperature rise of the components depends directly on the heat absorbed by the component. For brake disc, hence the temperature rise $(\Delta \mathrm{T})$ is given by

$$
(\Delta T)_{d}=\frac{H_{d}-H_{\text {convection }}-H_{\text {radiation }}}{m_{d} \times c_{d}}
$$

For the brake pad, convection and radiation losses are very less since it is enclosed inside the caliper.

$$
(\Delta T)_{p}=\frac{H_{p}}{m_{p} \times c_{p}}
$$

\section{Methodology}

\subsection{Determination of brake force}

To find the heat generated, we need to find the brake force acting on the brake disc. This can be calculated by knowing the brake pressure. The brake pressure variation can be found out from the data obtained by the brake pressure sensor. Hence the force acting on the rotor is found by multiplying it with the area of the caliper piston and the friction force can be found by multiplying the coefficient of friction of the brake pad and the disc as shown in Equation (3).

\subsection{Determination of heat generated}

To determine the heat generated due to the change in kinetic energy of the car, the power generated on the disc and pad contact can be calculated by using Equations (2). Change in disc velocity can be calculated using the wheel rpm data. The data is used only when the change in velocity is negative which signifies brake application as the heat is only generated during braking. For all the other time steps the heat input is given as zero. This data is inputted as heat generated on the pad- rotor contact in ANSYS Thermal. The heat input is balanced by the convection coefficient to

\begin{tabular}{|c|c|c|c|c|c|c|c|c|}
\hline Time(s) & velocity of $\operatorname{car}(\mathrm{m} / \mathrm{s})$ & brake pressure $(\mathrm{Pa})$ & brake force $(\mathrm{N})$ & wheel rpm & Tangential velocity of Brake disc(m/s & energy of the Disc(J) & heat input & convection coefficient \\
\hline 0 & 0 & 110375.5834 & 0 & 0 & 0 & 0 & 0 & 0 \\
\hline 0.1 & 0.161864 & 126674.5609 & 265.0660121 & 13.63636364 & 0.125085227 & 33.15584236 & 0 & 2.85366232 \\
\hline 0.2 & 0.323727 & 110375.5834 & 230.9604667 & 27.27272727 & 0.250170455 & 57.77948493 & 0 & 5.70730701 \\
\hline 0.3 & 0.971182 & 126674.5609 & 265.0660121 & 81.81818182 & 0.750511364 & 198.9350542 & 0 & 17.12193866 \\
\hline 0.4 & 1.456773 & 126674.5609 & 265.0660121 & 122.7272727 & 1.125767045 & 298.4025812 & 0 & 25.68290799 \\
\hline 0.5 & 1.456773 & 110375.5834 & 230.9604667 & 122.7272727 & 1.125767045 & 260.0076822 & 38.394899 & 25.68290799 \\
\hline 0.6 & 1.942364 & 142990.9261 & 299.2079408 & 163.6363636 & 1.501022727 & 449.1179194 & 0 & 34.24387732 \\
\hline 0.7 & 1.942364 & 110375.5834 & 230.9604667 & 163.6363636 & 1.501022727 & 346.6769096 & 102.44101 & 34.24387732 \\
\hline 0.8 & 2.266091 & 110375.5834 & 230.9604667 & 190.9090909 & 1.751193182 & 404.4563945 & 0 & 39.95118433 \\
\hline 0.9 & 2.589818 & 110375.5834 & 230.9604667 & 218.1818182 & 2.001363636 & 462.2358795 & 0 & 45.65849134 \\
\hline 1 & 2.913545 & 126674.5609 & 265.0660121 & 245.4545455 & 2.251534091 & 596.8051625 & 0 & 51.36579835 \\
\hline 1.1 & 2.913545 & 126674.5609 & 265.0660121 & 245.4545455 & 2.251534091 & 596.8051625 & 0 & 51.36579835 \\
\hline 1.2 & 3.237273 & 110375.5834 & 230.9604667 & 272.7272727 & 2.501704545 & 577.7948493 & 19.010313 & 57.07312299 \\
\hline 1.3 & 3.399136 & 110375.5834 & 230.9604667 & 286.3636364 & 2.626789773 & 606.6845918 & 0 & 59.92676768 \\
\hline
\end{tabular}
determine a working temperature of the brakes. The heat input to be given was calculated using an excel sheet taking all the necessary parameters into account. Fig. 3 shows the excel sheet used for heat input calculation and Fig. 4 shows the graph of the heat input to be given in ANSYS Thermal.

Fig. 3. Excel sheet of Heat Calculation 


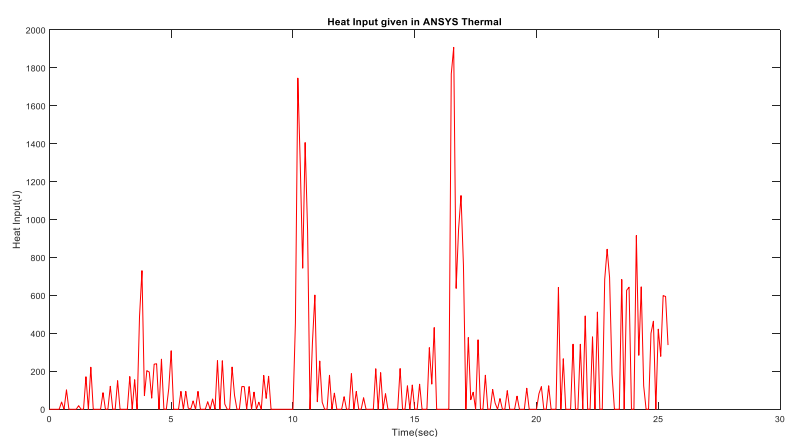

Fig. 4. Heat input given in ANSYS Thermal

\subsection{Modelling of CFD analysis for determination of convection coefficient}

Brake disc convective cooling has been historically studied by means of experimental and theoretical method and the optimization was only boosted with the advent of modern computational resources in the late 1980s [17]. To analyze the convection coefficient available due to the airflow on the rotor, the car was simulated in Star CCM+. The fluid domain size was defined as being 2 times the car length in front, 3 times the car length in the rear and 3 times the car width laterally. The shape of the first half of the car was Boolean subtracted from the fluid domain. All the Boolean subtracted faces were assigned their respective named selections namely car, wing, wheel and brake disc. Meshing was done using meshing tool. A volume of influence was used to refine the mesh around the car. Fig. 5 shows the CAD model used for CFD simulation. Table. 1 shows the imputs given in Star CCM+.

Table 1. Inputs given in Star CCM+

\begin{tabular}{|c|c|}
\hline Parameters & Inputs \\
\hline Solver type & Pressure based \\
\hline Model used & K epsilon, realizable \\
\hline $\begin{array}{l}\text { Reference } \\
\text { values }\end{array}$ & Computed from inlet \\
\hline Fluid used & Air \\
\hline Velocity inlet & inlet air velocity was given as $13.89 \mathrm{~m} / \mathrm{s}$ \\
\hline Pressure Outlet & The outlet pressure was defined as $1 \mathrm{~atm}$ \\
\hline Wheel & $\begin{array}{l}\text { The wheel was defined as a wall rotating } \\
\text { at } 60 \mathrm{rpm}\end{array}$ \\
\hline Brake disc & $\begin{array}{l}\text { The brake rotor was defined as a rotating } \\
\text { wall at the speed of } 60 \mathrm{rpm}\end{array}$ \\
\hline
\end{tabular}

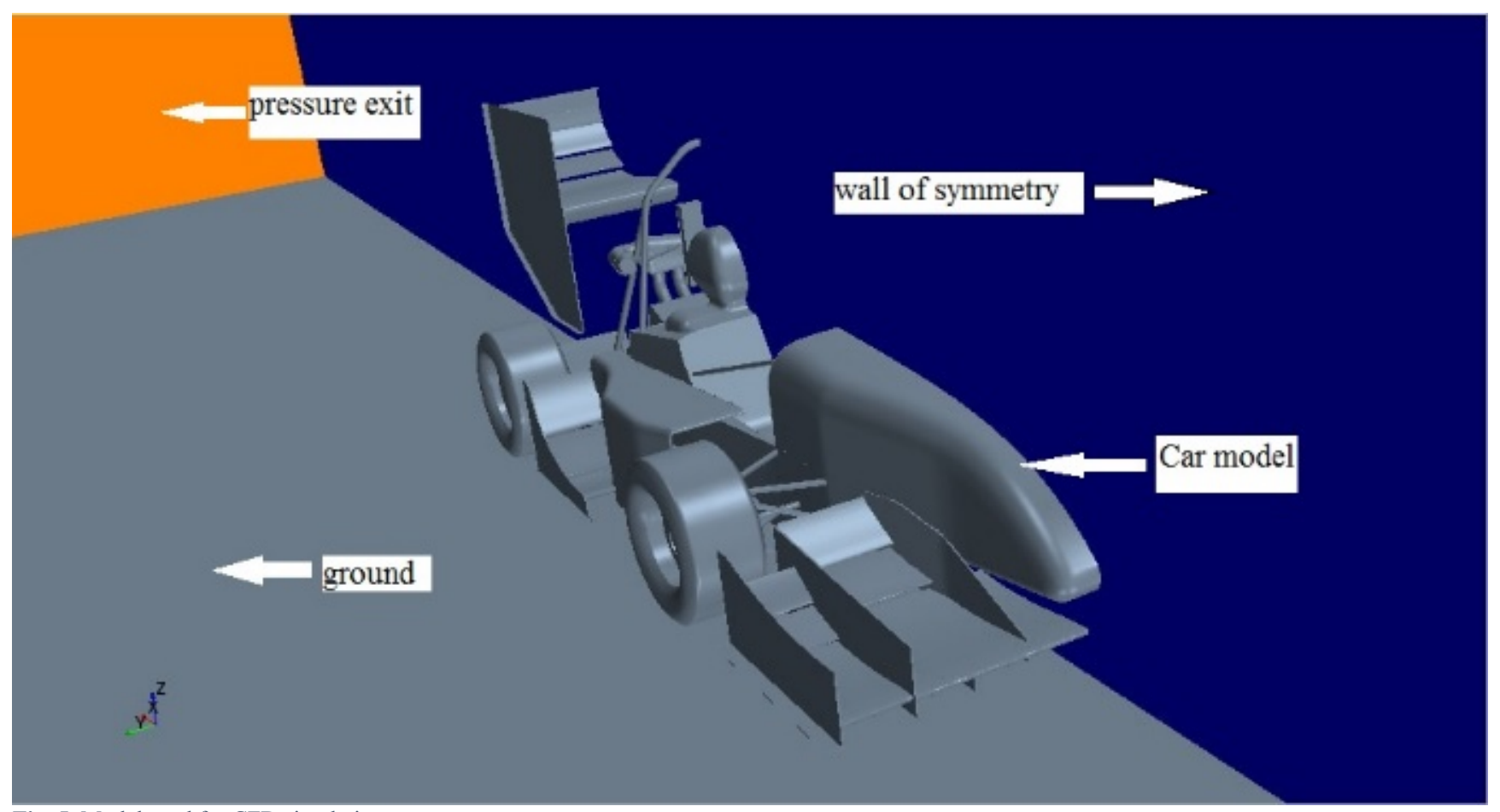

Fig. 5. Model used for CFD simulation

The goal of meshing in Workbench is to provide robust, easy to use meshing tools that will simplify the mesh generation process. The model used must be divided into a number of small pieces known as finite elements. Since the model is divided into a number of discrete parts, in simple terms, a mathematical net or "mesh" is required to carry out a finite element analysis [13]. The mesh had 1987512 nodes and 95695637 elements. Inflation layer was given with transition ratio of 0.27 on body, wing, wheel, brake disc and the boundaries of the fluid domain. Fig. 6 shows the mesh developed on the 3D model of the car. 


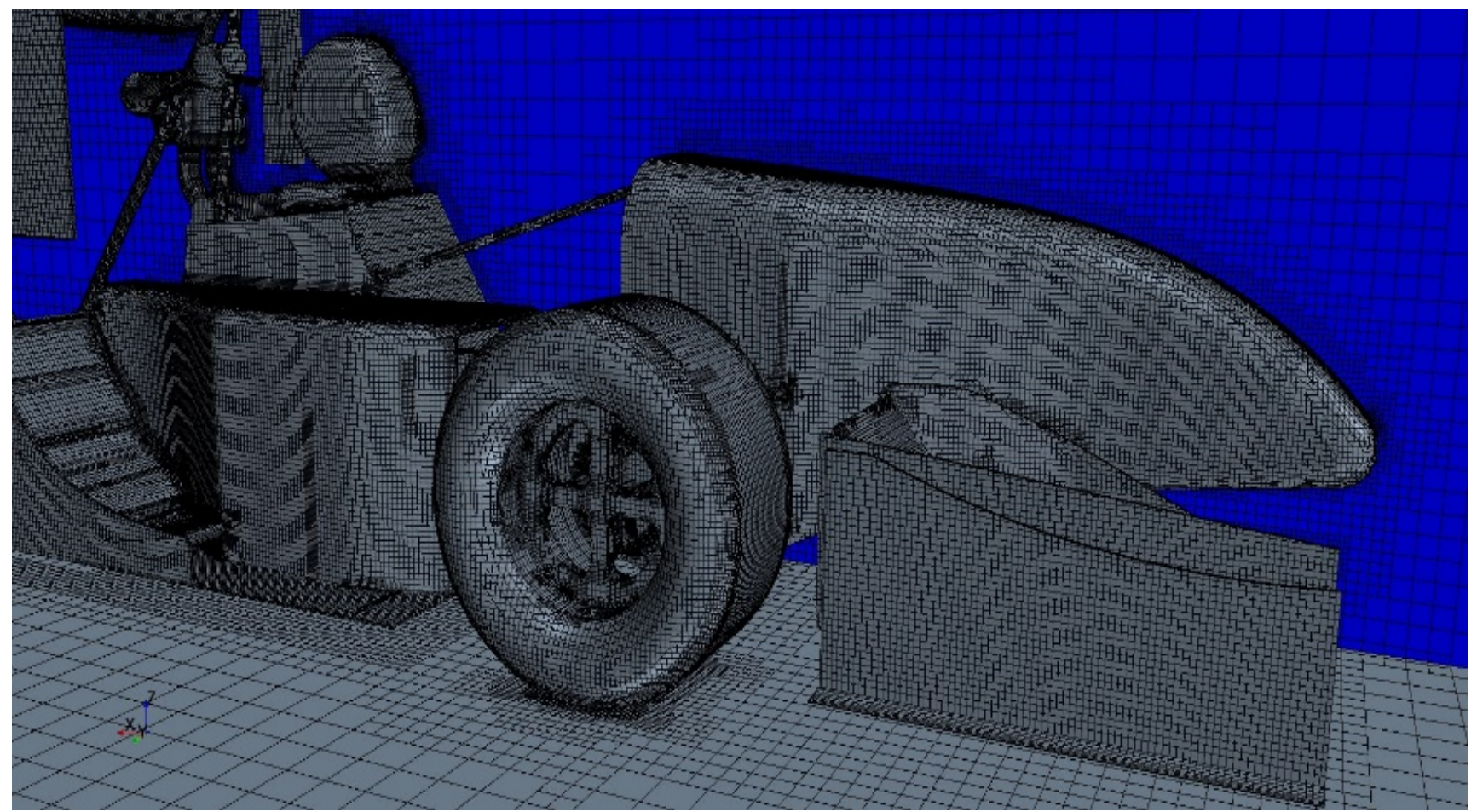

Fig. 6. Mesh used on the car model

Using these conditions, the flow of air near the rotor mounting area was analyzed and the convection coefficient available on the rotor was found out.

\subsection{Modeling the brake disc in ANSYS Thermal for finding the temperature rise}

Thermal module of ANSYS was used to determine the temperature rise of the components. Following are the types of Thermal Analysis [18]:

- A Steady State Thermal Analysis determines the temperature distribution and other thermal quantities under steady state loading conditions. A steady state loading condition is a situation where heat storage effects varying over a period of time can be ignored.

- A Transient thermal analysis determines the temperature distribution and other thermal quantities under conditions that vary over a period of time

Referring to the definition mentioned above, we concluded that transient analysis would be suitable for our simulation. The disc CAD model was uploaded in the designer modular of ANSYS Transient Thermal. The materials were selected from the materials library. Table. 2 shows the material properties. A refined mesh was used to ensure accurate results. The numbers of nodes in the mesh were 1313588 and the numbers of elements were 632757 . Fig. 7 shows the snap of mesh used in ANSYS Thermal.

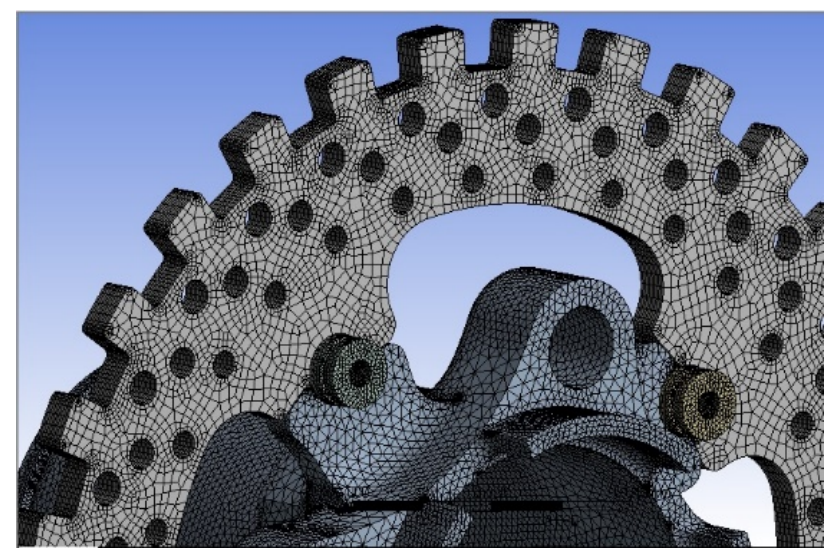

Fig. 7. Mesh used in ANSYS Thermal

Table 2. Disc material properties inputted in ANSYS Thermal

\begin{tabular}{c|c}
\hline Property & Value \\
\hline Density $\left(\mathrm{kg} / \mathrm{m}^{2}\right)$ & 7800 \\
Thermal Conductivity ( & 24.9 \\
W/m.K) & 460 \\
Specific Heat $(\mathrm{J} / \mathrm{Kg} . \mathrm{K})$ & 9.9 \\
Coefficient of Thermal & \\
Expansion $\left(\mu \mathrm{m} /{ }^{\circ} \mathrm{C}\right)$ &
\end{tabular}

The heat input which is calculated is given on the disc in 254 time steps each of 0.1 second since the duration of run was 25.4 seconds. The convection coefficient calculated using FLUENT, is entered on the rotor surface. The convection coefficient is given as calculated from Fig. 17 according to changing vehicle velocity. Fig. 8 shows the thermal loading on the brake disc. 


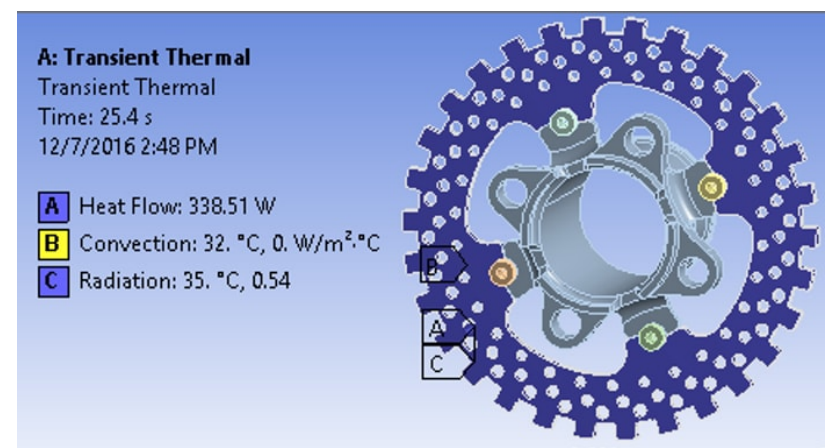

Fig. 8. Thermal loading on the Brake disc

The emissivity coefficient for radiation is given as 0.53 on the rotor. The output is selected as temperature distribution and temperature rise due to the heat input considering the heat losses is found. The assumptions which are made while modeling the process are given below [19].

- The brake disc material is considered as homogenous and isotropic.

- The problem domain is considered as axissymmetric.

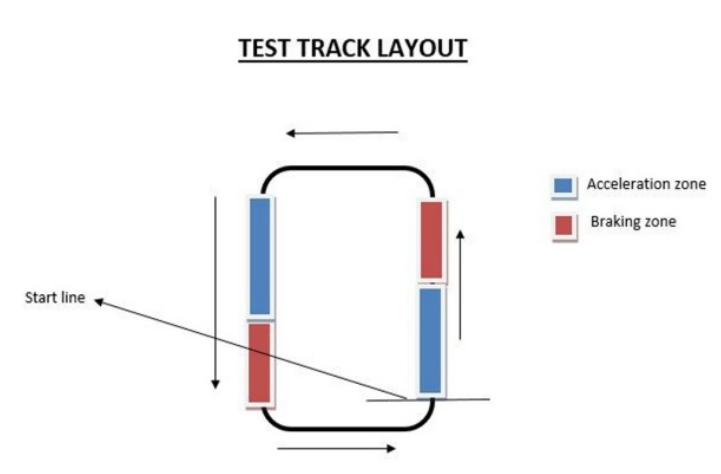

Fig. 9. Test Track layout and car on the track

The brake assembly was fitted with three sensors namely Texense infrared temperature sensor on the disc to measure the brake disc temperature, Honeywell hall effect sensor to measure wheel RPM and brake pressure sensors to log the changes in brake pressures. Fig. 10 shows the mounting of these sensors on the car. These sensors were logged using

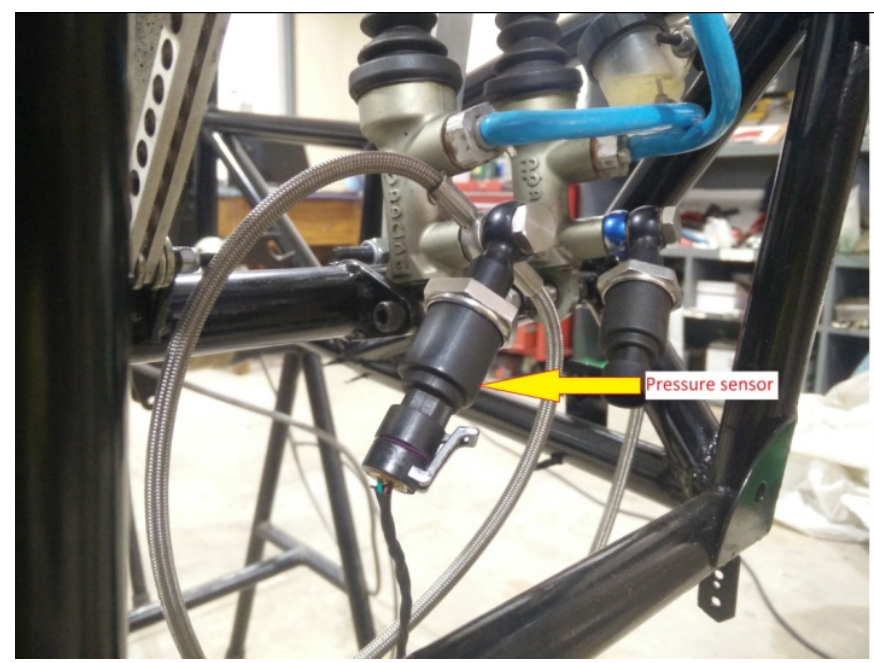

Fig. 10. Sensors mounted on the car
- Inertia \& body force effects are negligible during the analysis.

- No stress in brake disc before the application of brake.

- Brake disc is of drilled type.

- Thermal conductivity of the material used for analysis is constant.

- Only ambient air cooling is considered.

- Specific heat of brake disc material is constant \& does not change with temperature.

\subsection{Testing conducted on the car}

The test was carried out using the car and a track with 2 acceleration and braking zones respectively and 2 circular turns. The data to be obtained from the testing are brake pressure, wheel speed, and rotor temperature. While the brake pressure and the wheel speed would serve as the input for the numeric calculation and simulation, the brake disc temperature will be used to compare with the temperature obtained from the simulation to check for the accuracy of the simulation method. Fig. 9 shows the layout and the car on the track that was used for testing.

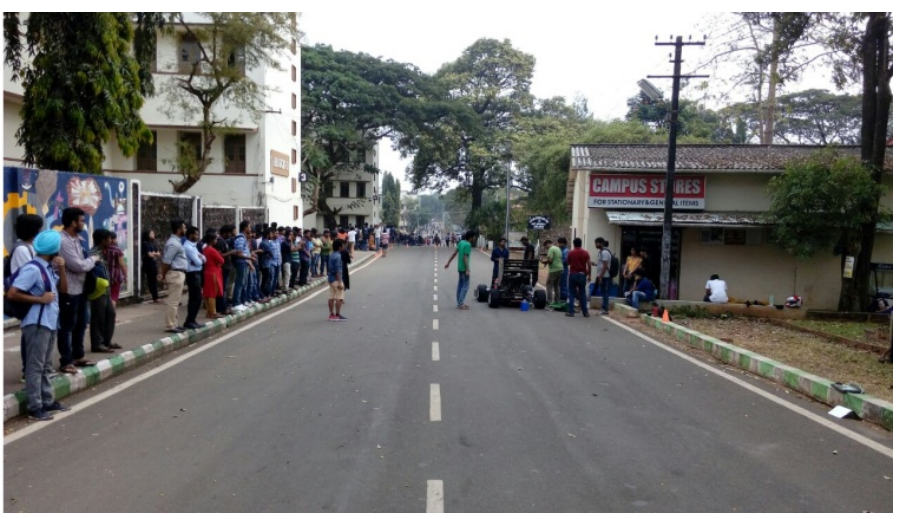

Myrio data logger mounted on the car with motec ECU. Hall Effect sensors uses the teeth on the brake disc which creates spikes in the output signal of the sensors. This is processed by measuring the amount of spikes per unit time and the RPM is found out.

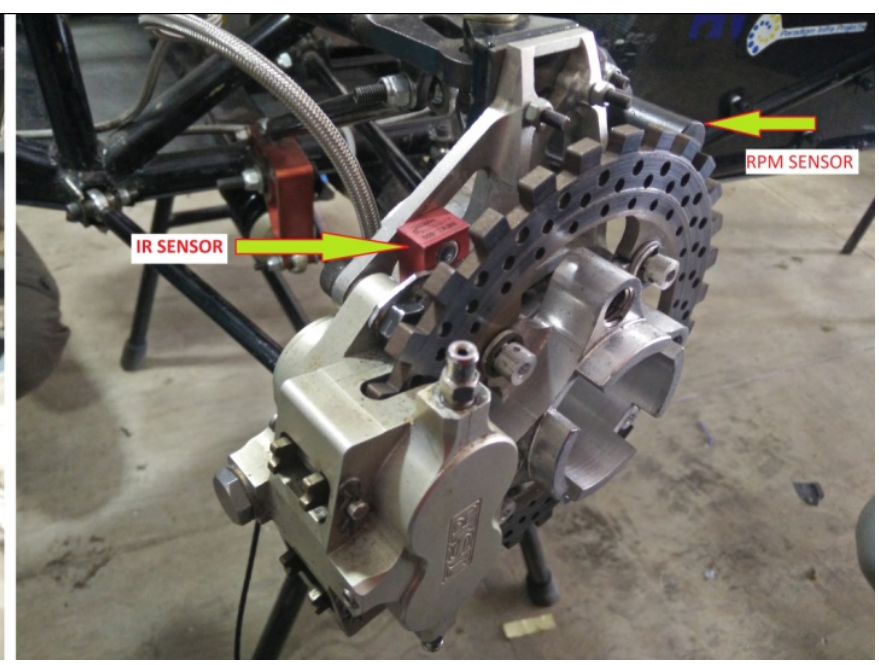




\section{Results}

\subsection{Convection coefficient on the rotor}

The flow around the wheels was simulated with the boundary conditions given in sub heading 3.3. The convection coefficient is determined as a wall function. The maximum convection coefficient of $243.5 \mathrm{~W} / \mathrm{m}^{2} \mathrm{~K}$ was observed on the disk at vehicle speed of $13.89 \mathrm{~m} / \mathrm{s}$. This was obtained from a plot on the rotor and will be used to calculate the heat dissipated by the rotor. The plot of convection coefficient vs. velocity of the car was plotted for the car running on the test track. Sofia Finnved and Sebastian Nöbbelin [20] has shown that the convection coeffiecient varies linearly with the car velocity.We calculated the convection coefficient when the car is standing still to be $5.15 \mathrm{~W} / \mathrm{m}^{2} \mathrm{~K}$. Hence we could plot a straight line showing the variation of convection coefficient with velocity. Fig. 11 shows the airflow on the car and the disc and Fig. 12 shows the variation of convection coefficient with car velocity.

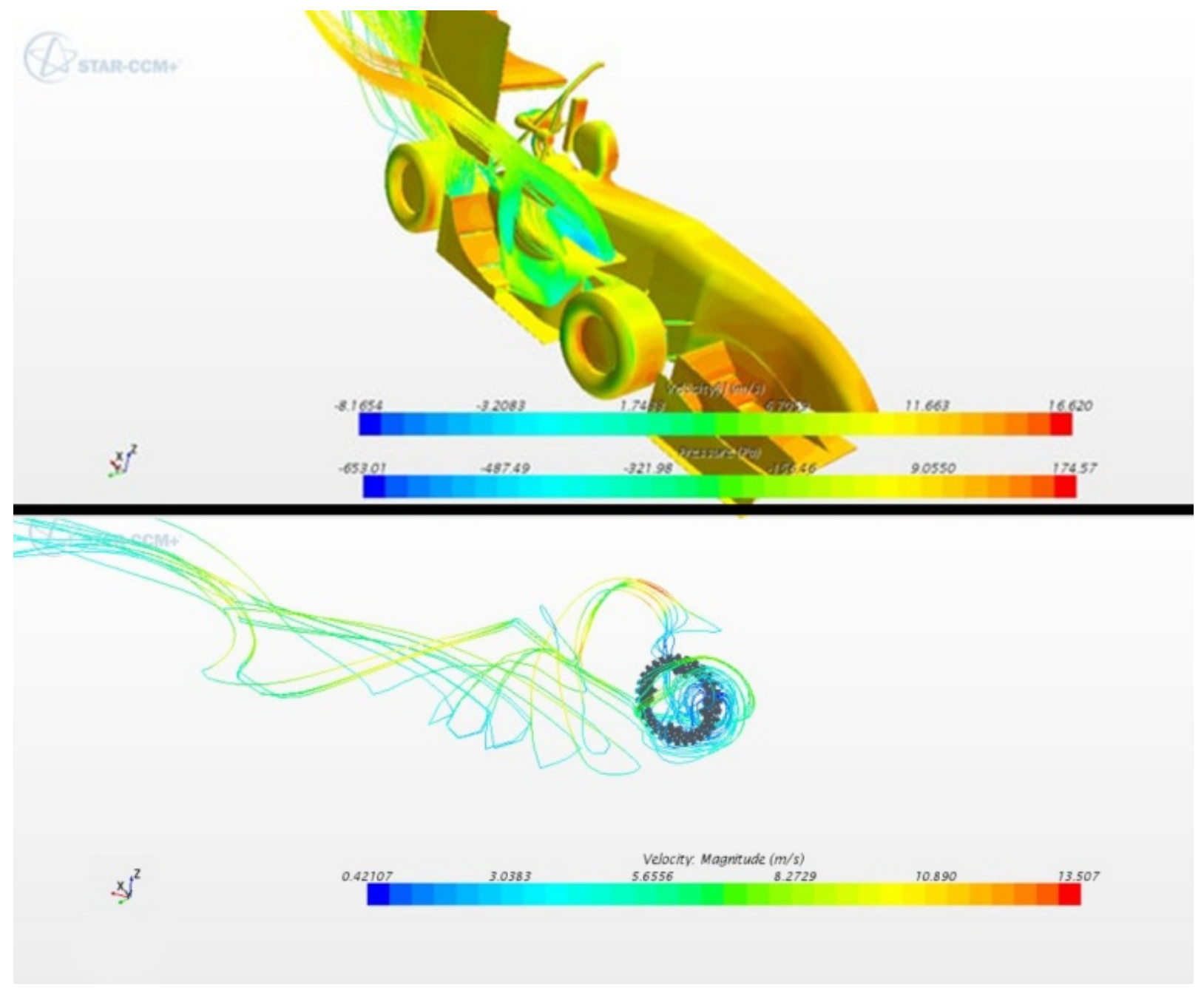

Fig. 11. Flow of air on the car and the disc

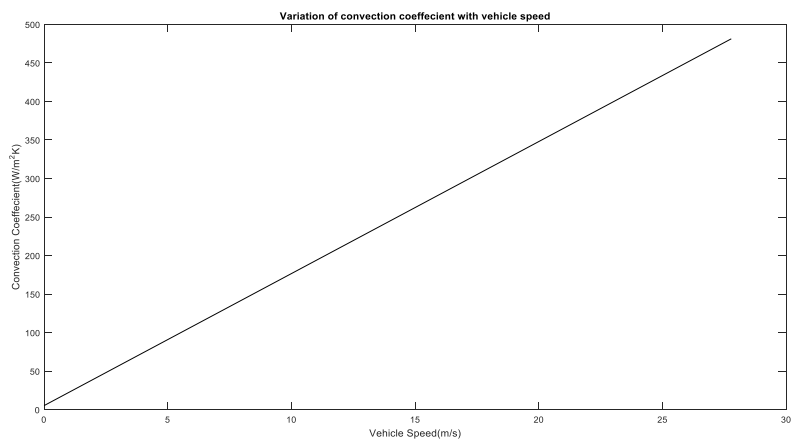

Fig. 12. Variation of convection coefficient with velocity

\subsection{Temperature of the brake assembly}

The temperature of the brake assembly is determined by giving the heat input calculated previously on the rotor pad contact surface. The temperature is plotted on the disc using ANSYS Transient Thermal module. The maximum temperature reached by the brake disc is 61.281 degree Celsius. A graph of variation of temperature with time is also obtained. The graph shows increase in temperature with each braking. This graph will be used to compare the disc temperature obtained from simulation with that obtained from the actual testing of the car. Fig. 13 shows the plot of temperature on the brake disc and Fig. 14 shows the predicted variation of brake disc temperature for 25.4 seconds. 


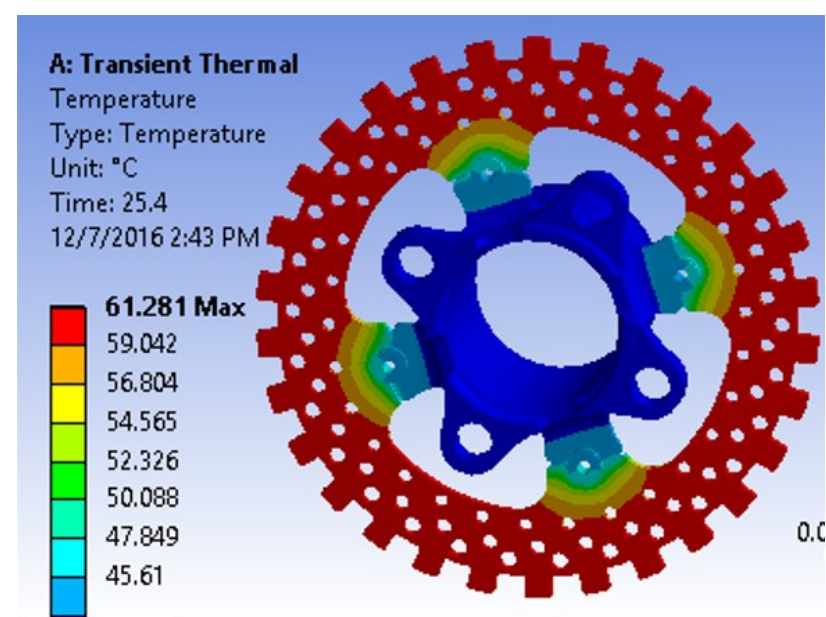

Fig. 13. Plot of temperature on disc

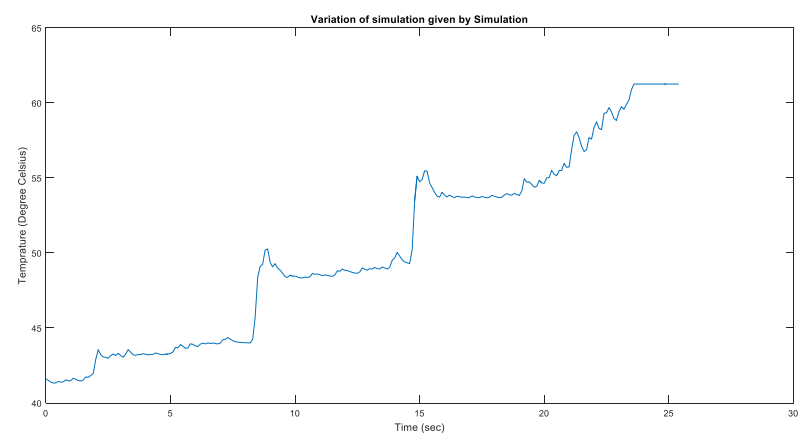

Fig. 14. Variation of temperature given by simulation

\subsection{Temperature obtained from Testing}

The temperature obtained from the testing with the sensors on the car was carefully analyzed. The data was plotted as a graph to see the variation of temperature during the test and compare with the temperature graph obtained from simulation in ANSYS. The maximum temperature reached by the brake disc was 62.3 degree. The temperature went to increase with every braking application. The variation was bit rough as the brake disc was of drilled type and the sensor read the holes as drop in temperature. Fig. 15 shows the variation of temperature during the testing of the car.

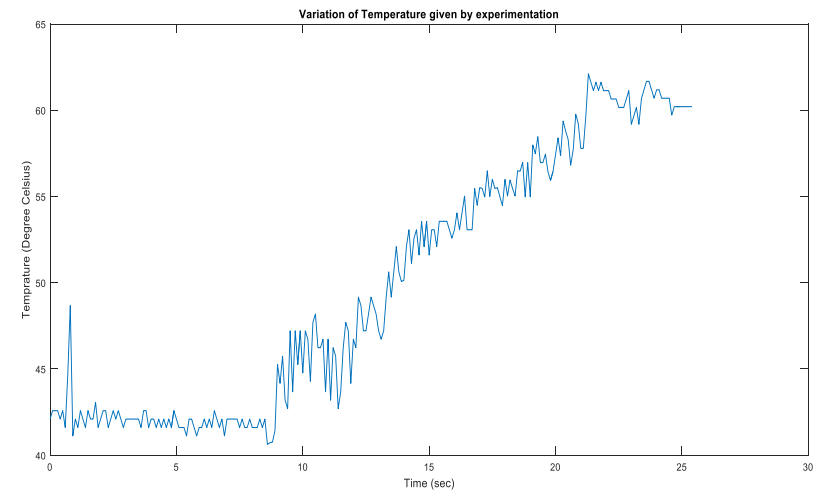

Fig. 15. Variation in Disc temperature obtained from experimentation

\section{Comparison of simulation and experimental results}

This is the most important step in the whole analysis as it shows how reliable the simulation is. The variation of the disk temperature observed is plotted with the temperature variation obtained from the simulation. It is observed that the the variation is almost similar in nature with aproximately same maximum temperature. The maximum temperature shown by the simulation graph is 61.28 degree celcius where as that obtained from the test graph is 62.3 degree celsius. The maximum difference in both the graps is of aproximitely $5^{\circ} \mathrm{C}$. Fig. 16 shows the comparison of the temperature variation obtained from the simulation a well as test run on the car.

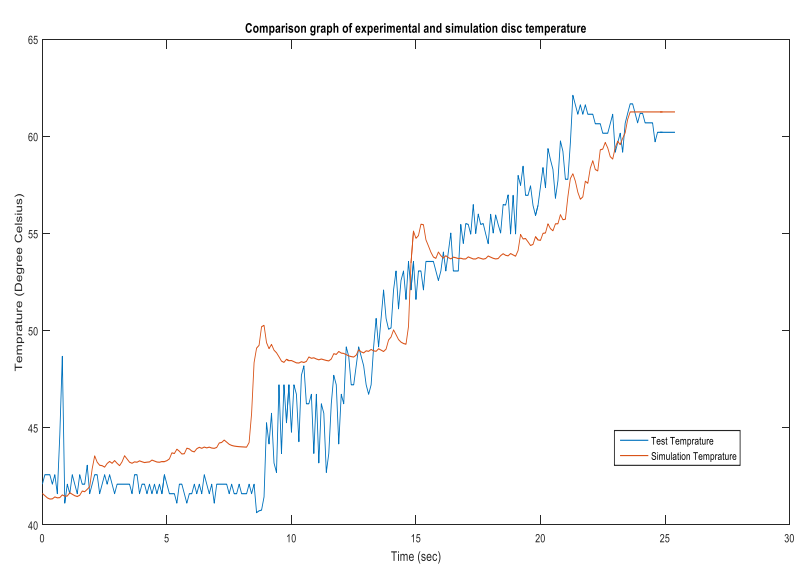

Fig. 16. Comparison graph of experimental and simulation disc temperature

\section{Determination of working temperature for the endurance race track}

The car specification such as weight, power, torque, height of center of gravity etc., are given as input in a lap time simulation software called as Optimum Lap. This software simulates the car on the endurance race track and gives car velocity and deceleration as output in the required time steps. Fig. 17 shows the endurance track used in Formula student Germany event.

This data can be used to calculate the heat input on the rotor using the method mentioned above in this paper and the temperature variation can be obtained for 8 laps of the endurance race track. The variation of temperature observed from this simulation is given in Fig. 18. Hence it can be deduced from Fig. 18 that the working temperature of the brakes is 300 to 500 degree Celsius for the endurance race track.

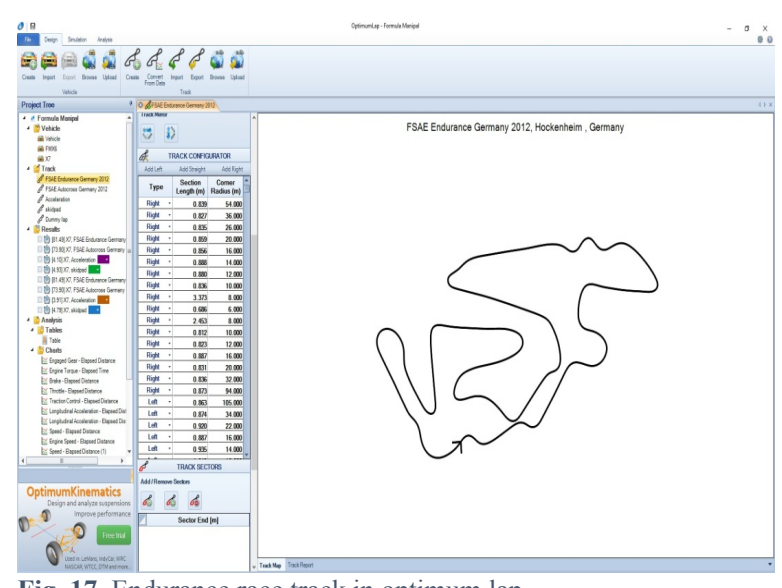

Fig. 17. Endurance race track in optimum lap 


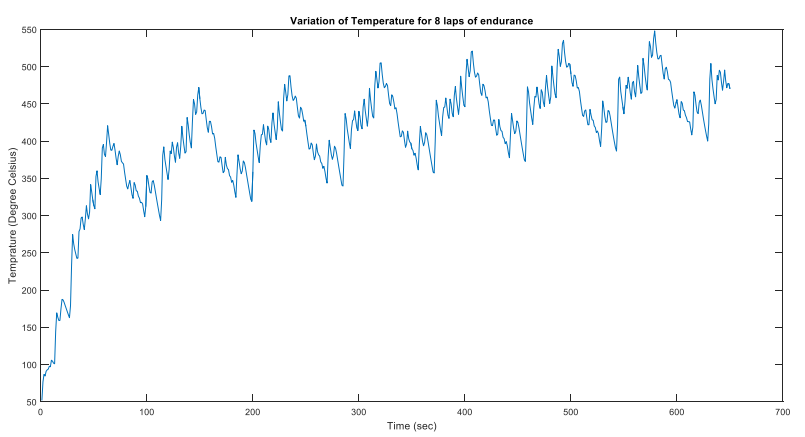

Fig. 18. Variation of temperature for 8 laps of endurance track

\section{Conclusion and Application}

We have used the velocity of the car to determine the heat generated due to braking and taken into account various factors that affect the net heat generation and dissipation from the brake disc. Thus we have determined the temperature rise in the brake disc and have found a working temperature range of the brakes. This method of finding the operating temperature of the brakes can be used for many purposes. As by knowing the operating temperature of the brakes in advance one can decide on the material used to manufacture the brake component like brake disc, caliper etc. as to withstand both thermal and mechanical loading. It also helps to decide the brake fluid to be used as brake fluids suitable for different working temperatures are available. Manufacturing of brake pads require the knowledge of operating temperature so that the peak of the coefficient of friction vs Temperature graph can be achieved in that temperature range using different combination of materials and thus maximum brake performance can be extracted from the brake pad.

\section{Acknowledgement}

I would like to acknowledge Manipal Institute of Technology for their constant support during this research. I would also like to thank Formula Manipal for the knowledge, motivation, prototype car and instruments they have provided for this research. This research wouldn't have been complete without the help of my college and team mates.

This is an Open Access article distributed under the terms of the Creative Commons Attribution Licence

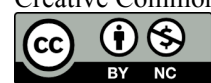

\section{References}

1. Gowtham.S, Manas M Bhat, "Elimination of Brake Fade in Vehicles by Altering the Brake Disc Size (A Concept)",International Journal of Innovative Research in Science, Engineering and Technology,Vol. 4, Issue 11, November 2015, DOI:10.15680/IJIRSET.2015.0411093

2. Rakesh Jaiswal, Anupam Raj Jha, Anush Karki, Debayan Das, Pawan Jaiswal, Saurav Rajgadia and Ankit Basnet, "STRUCTURAL AND THERMAL ANALYSIS OF DISC BRAKE USING SOLIDWORKS and ANSYS", International Journal of Mechanical Engineering and Technology (IJMET) Volume 7, Issue 1, Jan-Feb 2016, pp. 67-77, Article ID: IJMET_07_01_008.

3. Pradnya Kosbe, Chittaranjan More, "Characterization of Fade and Recovery Behavior of Brake Friction Material",INTERNATIONAL CONFERENCE ON CURRENT TRENDS IN TECHNOLOGY, 'NUiCONE - 2011'

4. Mr. Sachin Subhashrao Pujari Prof. Mr. K. M. Narkar,Mr. Kishor T. Phalke, "Structural Analysis and Thermal Analysis of Automotive Ventilated Brake Disc", IJSRD - International Journal for Scientific Research \& Development| Vol. 2, Issue 03, 2014 | ISSN (online): 2321-0613.

5. Shah E Alam, Yuvraj Vidhyadhar, Prashant Sharma, Abhishek Jain, "Thermal Analysis of disc Brakes Rotor: A comparative Report", Journal of Information Sciences and Computing Technologies (JISCT) ISSN: 2394-9066, Volume 3, Issue 2, April 20, 2015.

6. Manjunath T V, Dr Suresh P M, "Structural and Thermal Analysis of Rotor Disc of Disc Brake", International Journal of Innovative Research in Science, Engineering and Technology,Vol. 2, Issue 12, December 2013,ISSN: 2319-8753.

7. L. Kowal, K. Turewicz and T. Kruczek, "Measurements of temperature of brake disks in hoisting machines of mine shaft hoists", 11th International Conference on Quantitative Infrared Thermography, 11-14 June 2012, Naples Italy.

8. Faramarz Talati, Salman Jalalifar, "Analysis of heat conduction in a disk brake system", Heat Mass Transfer (2009) 45:1047-1059 DOI 10.1007/s00231-009-0476-y

9. Er.N.B.Shinde, Prof.B.R.Borkar, "C.A.D \&F.E.M analysis of disc brake system", International Journal of Engineering and Computer Science ISSN: 2319-7242.

10. Subhasis Sarkar, Prof. (Dr.) Pravin P. Rathod, "Review Paper on Thermal Analysis of Ventilated Disc Brake by Varying Design Parameters", International Journal of Engineering Research \& Technology (IJERT) ISSN: 2278-0181, Vol. 2 Issue 12, December $-2013$
11. Mr. Pengkam kenglang lungchan, Mr. Parag deshattiwar, Mr. Kahani menjo, Mr. Toshif ruikar, Mr. Sanjeet kumar, "A PROJECT ON "THERMAL ANALYSIS OF BRAKE DISC", Btech Project Department of Mechanical Engineering Government College of Engineering, Aurangabad (2014-2015).

12. Saeed Abu Alyazeed Albatlan, "Study Effect of Pads shapes on Temperature Distribution for Disc Brake Contact Surface",International Journal of Engineering Research and Development e-ISSN: 2278-067X, p-ISSN: 2278-800X, www.ijerd.com Volume 8, Issue 9 (September 2013), PP. 62-6762

13. Swapnil R. Abhang, D.P.Bhaskar, "Design and Analysis of Disc Brake", International Journal of Engineering Trends and Technology (IJETT) - Volume 8 Number 4- Feb 2014

14. Ali Belhocine, Mostefa Bouchetara, "Investigation of temperature and thermal stress in ventilated disc brake based on 3D thermomechanical coupling mode", Ain Shams Engineering Journal, Volume 4, Issue 3, September 2013

15. Arthur Stephens,"Aerodynamic Cooling of Automotive Disc Brakes",Msc Thesis, School of Aerospace, Mechanical \& Manufacturing Engineering RMIT University,March 2006.

16. Adam Adamowicz, Piotr Grzes, "Analysis of disc brake temperature distribution during single braking under nonaxisymmetric load", Applied Thermal Engineering, Elsevier, 2011, 31 (6-7), pp.1003.

17. A. belhocine, C.D.Cho, M.Nouby, Y.B.Yi, A. R. Abu Bakar, "Thermal analysis of both ventilated and full disc brake rotors with frictional heat generation", Applied and Computational Mechanics 8 (2014) 5-24.

18. Guru Murthy Nathi, T N Charyulu, K.Gowtham, P Satish Reddy, "COUPLED STRUCTUAL / THERMAL ANALYSIS OF DISC BRAKE", IJRET: International Journal of Research in Engineering and Technology,ISSN: 2319-1163,Volume: 01 Issue: 04 | Dec-2012

19. Ishwar Gupta, Gaurav Saxena, Vikas Modi, "Thermal Analysis Of Rotor Disc Of Disc Brake Of Baja Sae 2013 Car Through Finite Element Analysis", International Journal of Engineering Research and Applications (IJERA) ISSN: 2248-9622.

20. Sofia finnved, Sebastian Nöbbelin, "Temperature Estimation in Trailer Disc Brake", MSc Thesis ISRN LUTFD2/TFRT--5966-SE ISSN 0280-5316, Department of Automatic Control Lund University 


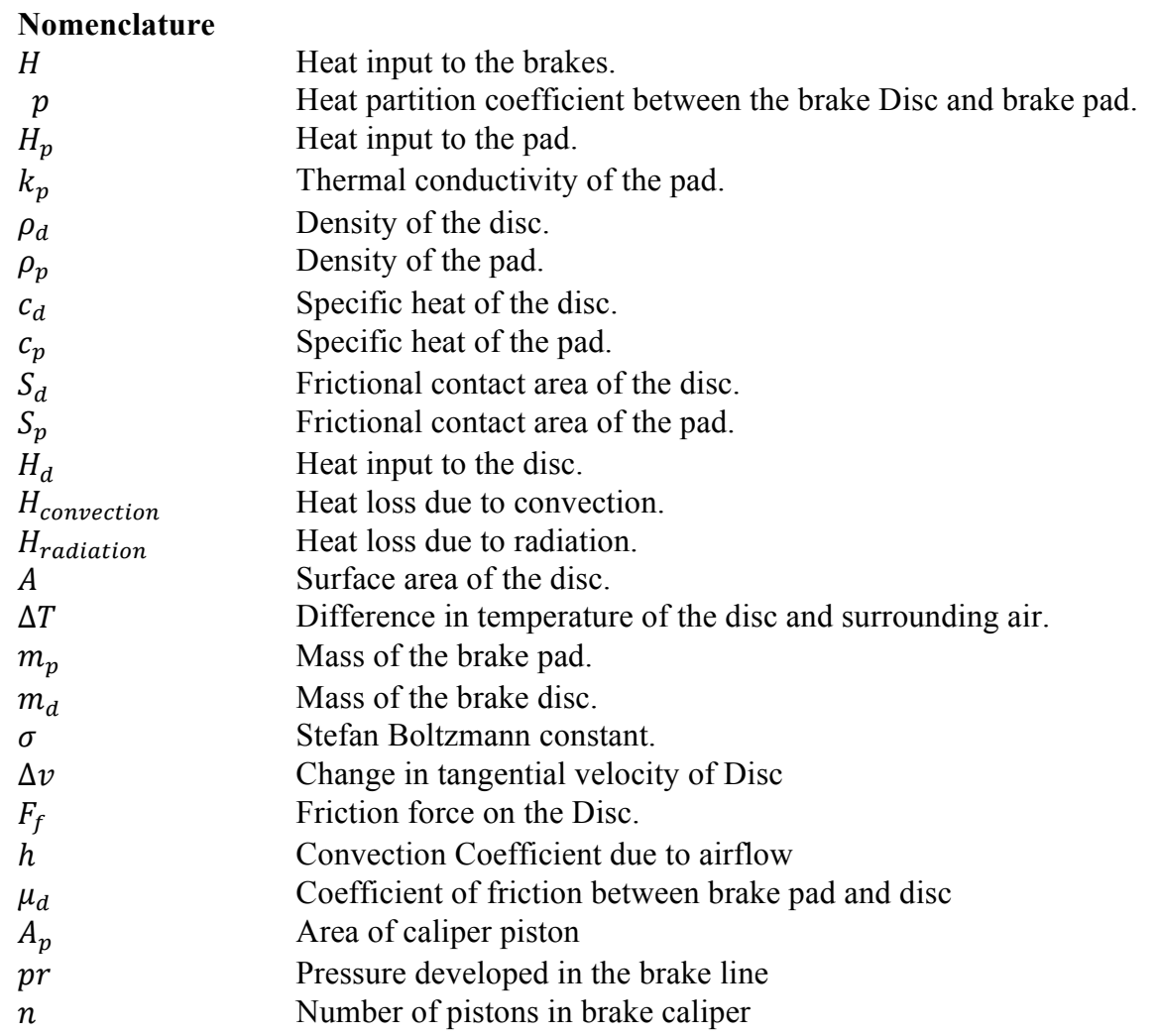

